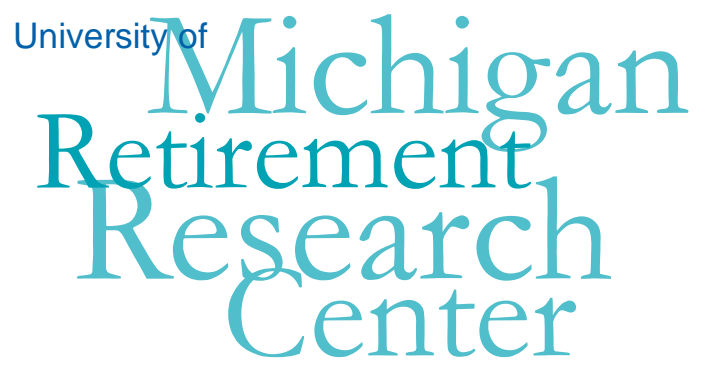

Working Paper WP 2011-258

\title{
Does Delay Cause Decay? The Effect of Administrative Decision Time on the Labor Force Participation and Earnings of Disability Applicants
}

\author{
David Autor, Nicole Maestas, Kathleen Mullen and Alexander Strand
}

\begin{tabular}{|l|l|}
\hline $\mathrm{M}$ & $\mathrm{R}$ \\
\hline $\mathrm{R}$ & $\mathrm{C}$ \\
\hline
\end{tabular}

Project \#: UM11-01 



\title{
Does Delay Cause Decay? The Effect of Administrative Decision Time on the Labor Force Participation and Earnings of Disability Applicants
}

\author{
David Autor \\ MIT and NBER \\ Nicole Maestas \\ RAND \\ Kathleen Mullen \\ RAND \\ Alexander Strand \\ Social Security Administration \\ September 2011 \\ Michigan Retirement Research Center \\ University of Michigan \\ P.O. Box 1248 \\ Ann Arbor, MI 48104 \\ http://www.mrrc.isr.umich.edu
}

(734) 615-0422

\section{Acknowledgements}

This work was supported by a grant from the Social Security Administration through the Michigan Retirement Research Center (Grant \# 5 RRC08098401-03-00). The findings and conclusions expressed are solely those of the author and do not represent the views of the Social Security Administration, any agency of the Federal government, or the Michigan Retirement Research Center. 


\title{
Does Delay Cause Decay? The Effect of Administrative Decision Time on the Labor Force Participation and Earnings of Disability Applicants
}

\begin{abstract}
An influential body of research studies the labor supply and earnings of denied Social Security Disability Insurance (SSDI) applicants to estimate the potential employment and earnings of those awarded benefits. This research design implicitly treats employability as a stable applicant attribute that is not directly impacted by the process of applying for SSDI benefits. If, plausibly, applicants' employment potential deteriorates while they are out of the labor force, then the labor force participation of denied applicants -- who spend an average of 10 months seeking benefits -may understate their employment potential at the time of application. This paper tests whether the duration of SSDI applications causally affects applicants' subsequent employment. We use a unique Social Security Administration workload database to identify exogenous variation in applicants' initial decision times induced by differences in processing speed among the disability examiners to which they are randomly assigned. This variation significantly affects applicants' total processing time but, importantly, is uncorrelated with their initial award and denial outcomes. We find that longer processing times reduce the employment and earnings of SSDI applicants in the years after their initial decision. A one standard deviation (2.4 month) increase in initial processing time reduces annual employment rates by 1 percentage point (3.2\%) in years two, three and four post-decision. Extrapolating these effects to total applicant processing times, we estimate that the SSDI determination process directly reduces the post-application employment of denied applicants by approximately 3.6 percentage points (7\%) and allowed applicants by approximately 5.2 percentage points (33\%).
\end{abstract}




\section{Introduction}

An influential body of research analyzes the causal effect of receipt of Social Security Disability Insurance benefits (SSDI) on employment and earnings by comparing the postapplication labor force participation of those awarded benefits relative to those denied benefits. ${ }^{1}$ Implicit in this analytic approach is the assumption that the SSDI determination process affects applicants' labor supply exclusively through a single causal channel— the allowance or denial decision. While this channel is undoubtedly of first-order importance, the SSDI determination process may affect post-application labor supply through other channels as well. Of particular note is the fact that SSDI applicants must engage in a prolonged period of labor force nonparticipation while they seek benefits. If applicants' employment potential deteriorates while they are out of the labor force, then the observed, post-application labor supply of denied and allowed applicants may understate their employment potential at the time of SSDI application. Moreover, if either the rate of deterioration or average SSDI determination time differs between allowed and denied applicants, a comparison of their post-SSDI determination labor supply may not identify the pure effect of the SSDI award on employment outcomes.

From the time that an SSDI application is filed to the time a final determination is made, the applicant is effectively barred from earning more than $\$ 1,000$ per month in paid employment, since this would exceed the Substantial Gainful Activity (SGA) threshold and result in a summary denial of benefits. The SSDI application process is typically lengthy, with several levels of determination and appeal. In our administrative sample of SSDI applicants, discussed

\footnotetext{
${ }^{1}$ Bound (1989) introduced the empirical approach of using the labor supply of denied SSDI applicants to form an upper bound on the potential labor supply of accepted applicants, an approach recently employed by von Wachter, Song, and Manchester (2011). Bound (1991) and Parsons (1991) debate the validity of this comparison. Several recent papers in this literature, including Chen and van der Klaauw (2005), French and Song (2011), and Maestas, Mullen and Strand (2011), exploit plausibly exogenous variation in SSDI awards to estimate the causal effect of receiving SSDI benefits on labor supply.
} 
below, the average time from SSDI application to final determination exceeds one year. Surprisingly, the mean determination time for allowed applicants significantly exceeds that of denied applicants (14.1 versus 9.7 months) because half of beneficiaries are allowed only after a lengthy appeal. Hence, both for those ultimately awarded and denied benefits, it appears plausible that the substantial time spent out of the labor force while applying for benefits may potentially have deleterious effects on skills, job readiness, and employability.

Due to the scale of the SSDI program, even modest deleterious effects of the SSDI application process on the subsequent labor force participation of applicants would have potentially economically significant implications. More than 22 million Americans applied for SSDI benefits in the past ten years, with approximately six million applications filed in the most recent eight calendar quarters alone. ${ }^{2}$

In this paper, we test whether the duration of the SSDI determination process affects the subsequent employment of allowed and denied applicants. We use a unique Social Security Administration workload database to identify exogenous variation in applicants' initial decision times induced by differences in processing speed among the disability examiners to which they are randomly assigned. The average examiner in our sample spends 3 months reviewing a case prior to making an initial determination. Mean determination times differ substantially across examiners, however, with the 90/10 range in mean examiner time equal to 2.2 months. Notably, the characteristics of applicants assigned to each examiner and geographic variation in processing times explain only a modest portion of cross-examiner variation. The remaining variation is likely primarily attributable to productivity differentials among Social Security Administration (SSA) employees.

\footnotetext{
${ }^{2}$ Statistics available at http://www.ssa.gov/OACT/STATS/dibStat.html, accessed 9/25/2011.
} 
Critical to our identification strategy, we show that this examiner-level variation in average processing times significantly affects applicants' total processing time but is uncorrelated with initial allowance and denial outcomes. In combination with the random assignment of applicants to examiners within a Disability Determination Service (DDS) office, these findings validate our use of examiner-specific mean processing times as instrumental variables for the realized processing time of the cases to which they are assigned.

Exploiting examiner-level variation, we find that longer processing times significantly reduce the employment and earnings of SSDI applicants in the years after their initial decision. Our main estimates indicate that a one standard deviation (2.4 months) increase in initial processing time reduces annual employment rates by about 1 percentage point $(3.2 \%)$ in years two and three following the initial determination. This effect remains robustly significant into the fourth post-determination year (the final year of our observation window).

To contextualize these numbers, we use them to estimate the impact of average applicant processing times on labor force participation of SSDI applicants. This calculation suggests that the SSDI determination process directly reduces the post-application employment of denied applicants by an average of approximately 3.6 percentage points $(6.8 \%)$ in years two and three following the initial determination and, similarly, reduces the average employment of allowed applicants by 5.2 percentage points (33\%). These calculations are arguably conservative because they ignore the fixed cost of any labor force withdrawal on subsequent employment.

Importantly, this paper presents the first causal estimates of the effect of application processing time on the subsequent labor supply of disability applicants. We show that the employment decay effect is a distinct causal channel through which the SSDI program impacts post-application labor supply outcomes - separate from the benefit receipt effect, which has been 
the exclusive focus of the literature to date. Combining the labor supply decay effect with a credible estimate of the benefit receipt effect suggests that the SSDI program effect on employment is nearly 25 percent larger than previously thought.

\section{Background on SSDI}

In order to apply for SSDI benefits, applicants must first reduce their earnings below SSA's threshold for "substantial gainful activity" (SGA), which is currently set at $\$ 1,000$ per month. Individuals apply for SSDI benefits at their local field office, which screens out those who are not currently insured or who are engaging in SGA (earning more than $\$ 1,000$ per month). Applications screened out at this level are labeled "technical denials," and do not receive a medical review. The remaining applications are forwarded to a state Disability Determination Services (DDS) office, where cases are assigned to disability examiners for review on a rotational basis. Exceptions to rotational assignment include high-priority cases flagged as potential terminal illness cases and, in some offices, cases with specific body system codes going to new examiners who are still in a "training" period which varies across DDS office. Otherwise, cases were randomly assigned to disability examiners within DDS office. See Maestas, Mullen and Strand (2011) for more details on the assignment process.

SSA employs a five-step review process in order to determine whether an applicant meets the definition of disabled - that is, unable to perform SGA given the severity of his impairment and/or vocational background (age, education and work experience). Figure 1 illustrates this process. The process is meant to resolve cases relatively quickly for applicants in both extremes of the severity distribution. Applicants with impairments that are obviously temporary or nonsevere are denied in step 2, and applicants with specific impairments deemed severe enough to 
warrant allowance into the program regardless of vocational background (i.e., they meet the criteria for "medical listings") are allowed in step 3. The remaining determinations take into account vocational considerations. Applicants who are deemed able to perform any of their past jobs are denied at step 4. Finally, applicants who are deemed able to perform any work in the current economy are denied, and applicants who are deemed unable to do any work are allowed, at step 5. These vocational allowance determinations are made in consultation with a medicalvocational grid which provides guidance based on residual functional capacity, age group, education and type of work experience (i.e., skilled, unskilled).

Denied applicants can appeal their initial determination, and the appeals process differs for applicants in "non-prototype" and "prototype" states. Before 1999, the procedure was the same in all states. Denied applicants could reapply for reconsideration by the original DDS office within 60 days of the initial determination. Applicants denied at reconsideration had an additional 60 days to file an appeal to have an administrative law judge (ALJ) review their case. In 1999, however, ten prototype states eliminated the reconsideration step of the appeals process and now applicants wishing to appeal in these states go directly to an ALJ. The states are: Alabama, Alaska, California (Los Angeles North and Los Angeles), Colorado (West), Louisiana, Michigan, Missouri, New Hampshire, New York and Pennsylvania. Applicants denied by an ALJ have additional opportunities to appeal to an SSA Appeals Council (AC) and finally to Federal Court. Figure 2 illustrates the different stages of the appeals process. At any stage in the appeals process the applicant can present new evidence. Appealing an initial determination can add several months and even years to the applicant's waiting time for a decision. An alternative path to overturning an initial determination is to submit a new application ("reapplication"). 
If an allowance is made, benefits commence after a five-month waiting period (from the alleged onset date) in which individuals may not perform SGA. Beneficiaries notified after the waiting period has elapsed may receive up to 19 months of back-dated benefits, but importantly they cannot go back in time to re-enter the labor market. Once the waiting period is over, beneficiaries enter a (not necessarily consecutive) nine-month Trial Work Period (TWP) and three-month Grace Period in which they may earn more than the SGA threshold without having their benefits suspended. Beneficiaries exhausting the TWP and Grace Period then enter a threeyear extended period of eligibility (EPE) in which benefits are paid for months in which earnings are below SGA, and not paid when earnings are above SGA.

\section{Model and Empirical Strategy}

We begin with a causal model of labor supply of the following form:

$$
y_{i}=X_{i} \beta+\delta t_{i}+\gamma D I_{i}-s_{i}+\varepsilon_{i}
$$

where $y_{i}$ is observed post-application labor supply of applicant $i, X_{i}$ denotes observed characteristics that influence labor supply (e.g., age, impairment), $t_{i}$ is applicant $i$ 's application processing time measured in months from the date of application until the date of allowance or final denial, $D I_{i}=1$ if the applicant was ultimately allowed benefits (i.e., is observed to be a SSDI beneficiary within 5 years of the initial determination), $s_{i}$ denotes unobserved impairment severity measured in terms of lost labor supply, and $\varepsilon_{i}$ is an idiosyncratic error term. The causal parameter of interest is $\delta$, which measures the labor supply decay rate, that is the loss in labor supply caused by an additional month of application processing time. 
Importantly, the decay rate $\delta$ is conceptually distinct from the causal effect of benefit receipt, $\gamma$, which has been the exclusive focus of the research literature to date. Figure 3 illustrates how the two effects are related. The vertical axis in Figure 3 measures post-application labor supply $y_{i}$ while the horizontal axis measures the application processing time $t_{i}$. The downward-sloping line in red gives post-application labor supply as a function of processing time for a denied applicant. The slope of the line is the decay rate $-\delta$. The slope of the corresponding green line for allowed applicants is assumed to be as for denied applicants with the same observed and unobserved characteristics as allowed applicants (that is, the allowance/denial decision can be thought of as the only difference between these groups of applicants).

Suppose applications were evaluated instantaneously at $t=0$. Then point $A$ is the observed post-application labor supply of the denied applicant, point $\mathrm{C}$ is the observed postapplication labor supply of the allowed applicant, and the distance AC measures $\gamma$, the causal effect of SSDI benefit receipt. In practice, however, applications are not evaluated instantaneously, so post-application labor supply is observed only after a period of processing time. If both allowed and denied applicants have application processing time $t_{i}=\bar{t}$, and the labor supply decay rate is the same for each, then the effect of processing time on labor supply is given by $\delta \bar{t}$. The combined effect of SSDI on labor supply operating through these two causal channels - processing time plus benefit receipt - is then $\gamma+\delta \bar{t}$. As noted above, the research literature has focused on estimating $\gamma$. The objective of this paper is to estimate $\delta$.

A key challenge for consistently estimating $\delta$ is that impairment severity, $s_{i}$, may affect processing time; that is, SSA may process severely ill applicants more rapidly than more 
ambiguous cases because the former are allowed at step 3 (i.e., meeting the listing) rather than at step 5 (i.e., capacity for any job) or on a subsequent appeal. If processing time is shorter for more severe ailments and $s_{i}$ is imperfectly observed, then OLS estimates of $\delta$ will be biased upward (towards zero) - that is, they will underestimate the decay rate. Intuitively, applicants with shorter processing times will be observed to have relatively low post-application labor supply (due to their unobservably poor health) while those with longer processing times will have higher post-application labor supply due to their relatively good health. In this case, estimates of the decay rate would be confounded with the direct effect of health on labor supply and would understate the health-constant adverse effect of additional waiting time on subsequent labor supply.

To overcome this confound, we employ an empirical strategy similar to that used by Maestas, Mullen and Strand (2011, MMS hereafter) to estimate the effect of SSDI benefit receipt on labor supply $(\gamma)$. MMS present evidence that DDS examiners differ in the implicit thresholds that they employ when judging the severity of a disability. All else equal, applications sent to low-threshold examiners are more likely to be allowed than others whereas those sent to highthreshold examiners are more likely to be denied. MMS observe that because applications are randomly assigned to examiners, examiner-specific allowance rates can be used to instrument for the ultimate allowance decision for individual applicants, thereby identifying the causal effect of the allowance decision on labor supply.

In a similar vein to MMS, we take advantage of the fact that DDS examiners also vary considerably in their rate of processing disability applications; some DDS examiners are considerably faster than others. Using the random assignment of cases to DDS examiners, this natural variation in examiner processing speed during the initial determination phase generates 
exogenous variation in total processing time (which includes time spent in the appellate phases) which is uncorrelated with applicants' unobserved severity $s_{i}$. Thus, we can use examiner assignments to isolate exogenous variation in applicant processing times that is independent of impairment severity. The instrumental variable we employ in our analysis is the average processing time of examiner $j$ to which applicant $i$ is randomly assigned, excluding applicant $i$ 's own processing time: $\operatorname{EXTIME}_{i j}=\frac{1}{N_{j-1}} \sum_{k \neq i, k=1}^{N_{j}} t_{k}$.

While this identification strategy breaks the correlation between $t_{i}$ and $s_{i}$, there remains the possibility of a correlation between the instrument $E X T I M E_{i j}$ and the indicator for ultimate allowance, $D I_{i} \cdot{ }^{3}$ As we show later in Table 8, while $E X T I M E_{i j}$ is not correlated with the likelihood of initial allowance, it is positively correlated with both the likelihood of appeal and, ultimately, with the likelihood of benefit receipt. That is, all else equal, an applicant initially denied by a slower DDS examiner is more likely to appeal than one denied by a faster DDS examiner. This could plausibly arise if an applicant assigned to a slower examiner experiences a greater decay in employability in the initial determination phase (as implied by Figure 3), and consequently has a lower opportunity cost of remaining out of the labor force while pursuing an appeal.

The reduced form effect of EXTIME $E_{i j}$ on labor supply encompasses the total effect of DDS examiner processing speed — the direct effect of processing time on labor supply and an indirect effect of processing time operating through the channels of appeal and subsequent benefit receipt. The IV estimate of $\delta$ (instrumenting for $t_{i}$ with $E X T I M E_{i j}$ ) attributes both direct

\footnotetext{
${ }^{3}$ Note that $D I_{i}$ is also an endogenous regressor correlated with $S_{i}$.
} 
and indirect effects to $t_{i}$. In Figure 3, the gray dashed line shows how if the decay rate includes both the direct and indirect effects, the reduction in labor supply attributed to processing time is larger (distance $A B^{\prime}$ instead of $A B$ ) and includes part of the effect of benefit receipt already captured by $\gamma$. Because of this overlap in the estimates, one cannot simply add the decay effect to the benefit receipt effect as shown above, $\gamma+\delta \bar{t}$; doing so would overstate the impact of SSDI.

The direct effect can potentially be isolated, however, by estimating $\delta$ on the subsample of initially allowed applicants, since for these applicants there is no appeal and as we show later EXTIME $_{i j}$ is uncorrelated with the probability of initial allowance-which in this case is equivalent to ultimate allowance. The key assumption underlying this strategy is that the true decay parameter $\delta$ is the same for both allowed and denied applicants (when this is the case, distance $A B=C D$ in Figure 3$)^{4}$

Figure 3 also shows how a correlation between processing time and ultimate benefit receipt can similarly affect the estimate of $\gamma$ in a regression of labor supply on benefit receipt, when processing time is omitted as an (endogenous) regressor. If, for example, the ultimately allowed applicant experiences a longer processing time than the denied applicant, $\vec{t}>\bar{t}$, then the estimated $\gamma$ will include both the direct effect of allowance on labor supply (distance $B D$ ) plus an indirect effect from the decay associated with the additional processing time (distance $\left.D D^{\prime}=\delta\left(\vec{t}^{\prime}-\bar{t}\right)\right)$. However, with an unbiased estimate of $\delta$ and known average processing times for allowed and denied applicants, the direct effect of benefit receipt on labor supply can

\footnotetext{
${ }^{4}$ This assumption is fundamentally untestable. Although in Table 6, the estimated decay parameter is smaller for the initially allowed than for the initially denied, estimates produced using the initially denied sample include both direct and indirect effects (and thus should be bigger). It remains possible, however, that the decay parameter is in reality smaller for allowed applicants, either due to the income or substitution effects of SSDI receipt, both of which would be expected to reduce labor overall force participation in this group.
} 
be recovered by subtracting $\delta(\bar{t}-\bar{t})$ from the estimated $\gamma$. With this adjustment, one could construct an estimate of the combined effects of benefit receipt and decay, $\gamma+\delta \bar{t}$. In the next sections, we present our estimate of $\delta$ and discuss the combined effects of SSDI on labor supply operating through both the decay and benefit receipt channels.

\section{Data and Caseload Characteristics}

We make use of a unique workload management database called the Disability Operational Data Store (DIODS) which temporarily stores information about the universe of initial and reconsideration disability decisions that are recorded in the National Disability Determination Service System. The main advantage of the DIODS over other data sets is that it includes alphanumeric codes linking applicants to the DDS examiner who considered their case. Our extract was made in December 2009 and contains data on all initial medical determinations (that is, excluding technical denials) made in 2005 . We restrict our sample to primary claimants (i.e., excluding dependents) for adults ages 18-64 assigned to examiners handling at least 10 such cases (and fewer than 900 cases) in 2005. In addition to the outcome of the determination, the DIODS includes information on application filing date, date of receipt at the DDS office (after being forwarded from the field office) and the date of determination. We compute $E X T I M E_{i j}-$ our leave-one-out measure of examiner processing time - using time at DDS (date of determination minus date of receipt at DDS). The results of reconsideration decisions for applications initially denied in 2005 were obtained from a DIODS extract including decisions through the end of 2006. An audit study performed by the Office of the Inspector General (2008) found that on average reconsiderations were processed within 94 days of their initial determination in 2006, including the 60 day window that applicants have to initiate an appeal. 
In order to measure total waiting time for applicants who appealed beyond the reconsideration level, we link the DIODS sample to data on ALJ hearings from the Case Processing and Management System (CPMS), where we observe the date of decision for both affirmations and reversals (through June 2011). We do not directly observe cases that proceed to higher levels of the appeals process (Appeals Council and/or Federal Court); however, we are able to identify decision dates for cases that were allowed at later stages of the appeals process, or through reapplication, by linking to the Payment History Update System (PHUS) and Master Beneficiary Record (MBR). For classification purposes, we count cases where the applicant received an SSDI payment but was observed as a denial at the ALJ stage as a "higher appeals" decision, whereas we count cases where an applicant received an SSDI payment before the ALJlevel decision or was not observed to file an ALJ claim as a "reapplication." We observe these payments through December 2010.

For a small fraction of cases denied at upper levels of the appeals process or through reapplication, and for any cases still in process more than 5 years after the initial determination, we will underestimate true waiting time. Table Al shows the percentage of claimants initially denied in 2005 who were subsequently denied by an ALJ and who are later observed receiving benefits, as well as the percentage of claimants initially denied in 2005 who we do not observe initiating an appeal and who are later observed receiving benefits (i.e., through reapplication). For both types of cases, less than $15 \%$ are observed receiving benefits 5 years after their initial denial. Thus, assuming conservatively that half of individuals in these groups were denied at later stages (which we do not observe) or were still in process, then the final processing times of 
no more than 7,826 applicants are censored at their ALJ decision ( $0.7 \%$ of the sample) and no more than 44,773 applicants are censored at their initial determination (4\% of the sample). ${ }^{5}$

Finally, we observe labor market outcomes by linking our sample to the Detailed Earnings Record (DER) that gives uncapped annual earnings from box 5 (Medicare wages and tips) of individuals' W2 tax forms. We observe earnings up to and including 2009. In order to ensure that the earnings records represent a full year of potential work, we link to the date of death information in the Numerical Identification System (NUMIDENT) and restrict the sample to applicants who were alive through the end of the calendar year in which earnings are observed.

Table 1 presents summary statistics for our sample, overall and separately for applicants in non-prototype vs. prototype states, and by initial and final allowance decision. Three-quarters of applicants are in non-prototype states vs. one-quarter in states that have streamlined the appeals process by eliminating reconsideration. Although only one-third of applicants are allowed at the initial determination stage, two-thirds of applicants ultimately receive benefits. Indeed, more than half of all initially denied applicants were receiving SSDI benefits by 2010, five years after their initial determination. Examiner waiting time, or $E X T I M E_{i j}$, is 3 months on average and balanced across the different groups. Applicants in prototype states, while slightly less likely to appeal an initial denial, were more likely to be allowed on appeal. Slightly more applicants were observed to receive benefits by 2010 in prototype vs. non-prototype states. Approximately half of SSDI claims are concurrent with claims for Supplemental Security Income (SSI), which pays additional benefits to disabled individuals with limited income

\footnotetext{
${ }^{5}$ In reality it is likely that applicants who choose to reapply rather than pursue an appeal have higher success rates (e.g., their functional limitations worsened or they more fully documented their existing limitations).
} 
(counting SSDI) and resources. Applications are assigned to examiners and evaluated the same way for concurrent and non-concurrent applications.

Fewer than $1 \%$ of applications are flagged as high priority terminal illness cases, and these cases have disproportionately high allowance rates. On average, applicants are 46.7 years old at the time of their initial determination, and have low pre-onset earnings - $\$ 22,729$ (in $2008 \$$ ) averaged over the 3-5 years prior to initial determination. Earnings and employment 2-4 years after the initial determination are also low, and falling over time.

Table 2 presents summary statistics for application processing times measured in months, separately for non-prototype and prototype states. Panel A displays cumulative waiting times at different administrative levels, and Panel B displays the time the application spent at the DDS office, for all applications and grouped by final stage of the disability determination process (see Figure 1). On average, applicants wait just under 4 months for an initial determination from the date they filed the application. The median waiting time is slightly smaller -3.4 and 3.3 months for applications in non-prototype and prototype states, respectively. Approximately $10 \%$ of applications in both types of states have initial waiting times of 6 months or longer. About 3 months of this time is spent at the DDS office under review by a DDS examiner. As expected, applications that were allowed or denied at earlier stages in the disability determination process have shorter waiting times on average than applications evaluated at later stages that incorporate vocational criteria.

Even if there is wide variation in initial waiting times at the applicant level, if applicants are (conditionally) randomly assigned to examiners it does not necessarily follow that there is significant variation in average waiting times at the examiner level. Table A2 presents summary statistics at the examiner level and Figure 4 presents a kernel-density smoothed histogram of 
deviations in examiner time from average time at DDS (3 months), unadjusted and adjusted for case-mix differences. (That is, we first regress $E X T I M E_{i j}$ on DDS dummies and fraction of cases with the following characteristics: 3-digit zip code, body system code, flag for terminal illness (high priority case), age group, average pre-onset earnings and concurrent status; and we plot the residuals from this regression.) Adjusting for case-mix differences tightens the distribution of examiner times, reducing the standard deviation from 1 month to 0.68 months, but there is still a significant amount of variation in average waiting times at the DDS level.

Despite having initial waiting times of generally less than 6 months, SSDI applicants spend more than 1 year waiting for a final decision, and $10 \%$ of cases spend almost 3 years or longer, as they navigate a complex system of appeals. In the non-prototype states, initially denied applicants who appeal for reconsideration wait an additional 5 months for a decision on average, and applicants further appealing to an Administrative Law Judge (ALJ) wait an additional 2 years. Despite eliminating the reconsideration step in the prototype states, applicants appealing directly to the ALJ level waited only 3.9 fewer months than applicants appealing to an ALJ after being denied at reconsideration (although more applicants reached the ALJ stage in prototype states than in non-prototype states). Generally, applicants in prototype states do not appear to have significantly shorter waiting times than applicants in non-prototype states.

Although we only observe waiting times for individuals who are ultimately allowed at later stages of the appeals process (Federal Court or Appeals Council), we see that this process adds an average of 15.1 months in non-prototype states and 15.9 months in prototype states, for cumulative waiting times of 47.5 and 44.5 months, respectively, (almost 4 years) for this small fraction of applications. Finally, about $2.6 \%$ of applicants were observed to receive benefits even though we observe no appeals decision, presumably awarded through an additional application, 
and the benefits are received about 33 months from the filing of the initial application. If we assume that approximately equal numbers of applicants at these stages were denied (which we do not observe) then we can conclude that we underestimate average time to last decision by 1 month at most among all applicants.

Table 3 breaks down average time at DDS and total waiting time (i.e., time to last observed decision) by ultimate disposition of the case. There are not large differences in initial waiting times among any of these groups, but whether an applicant goes on to appeal has a very large impact on final waiting time. (As discussed above, due to data restrictions final waiting times are slightly understated for applicants who were ultimately not allowed.) Thus, applicants who appealed their initial determination spent six times longer waiting for a decision, regardless of the ultimate disposition of the case. However, because approximately half of ultimately awarded applicants pursued an appeal or reapplication, whereas less than one-third of ultimately denied applicants did, average final waiting times are 4.4 months longer for those ultimately allowed.

\section{Results}

\subsection{First Stage Regressions}

Table 4 presents first-stage regression estimates of the effect of our instrument $E X T I M E_{i j}$ on $t_{i}$, applicant time until final decision, for the full sample of SSDI applicants and particular subsamples. In each column, we display the coefficient on EXTIME $E_{i j}$ obtained under three different specifications. The first specification is an OLS regression specification with no controls. The second is a specification that includes the "assignment variables" (DDS indicators, terminal illness flag, and body system code); that is, the variables that determine to which 
examiner a case is assigned, and which are necessary for our assumption of conditional random assignment. The third specification further adds applicant characteristics (age, pre-disability earnings, three-digit zip code), and is included as a randomization test — if the coefficient on EXTIME $_{i j}$ is robust to the inclusion of individual characteristics, then our assumption of conditional random assignment is supported.

In the full sample (first column), the coefficient on $E X T I M E_{i j}$ exceeds one when we omit the necessary examiner assignment variables, but falls to 0.986 once they are included. In other words, a one month increase in examiner processing time leads to a nearly one-month increase in applicant time until final decision. The estimate is statistically unchanged once we add applicant characteristics, indicating that $E X T I M E_{i j}$ is not correlated with applicant characteristics (after conditioning on the assignment variables). ${ }^{6}$

We show the same sequence of first-stage coefficients separately for applicants who are initially allowed and initially denied and for applicants in non-prototype and prototype states. In the initially allowed sample, the first-stage coefficient is 0.847 ; the attenuation away from 1 is somewhat surprising since the initially allowed do not pursue appeals, and hence final time is uncensored and equal to initial processing time. The attenuation is most likely due to noise in EXTIME $E_{i j}$, which is computed over finite examiner caseloads. This suggests that in samples in which appeals are possible, the coefficient on EXTIME $E_{i j}$ should be at least as large as it is in the initially allowed sample, given that $\operatorname{EXTIME}_{i j}$ is positively correlated with the probability of subsequent appeal (see Table 8). This is indeed the case for the initially denied sample (as well as the full sample), where the first-stage coefficient is 1.06; in other words, the "appeal effect" of

\footnotetext{
${ }^{6}$ The incremental F-statistic $=307$, which indicates a strong first stage.
} 
$E_{X T I M E_{i j}}$ offsets the "small-sample attenuation effect" of EXTIME $E_{i j}$. The coefficients for the non-prototype states are similar to those for the full sample, which is not surprising since threequarters of applicants in our sample are in non-prototype states. The first-stage coefficient (conditional on assignment variables) for the prototype states is only 0.832 , which points to less of an offsetting appeal effect in prototype states, where the absence of a reconsideration stage means shorter waiting times conditional on appeal.

\subsection{Reduced Form Effect of Examiner Time on Labor Supply Outcomes}

We next turn to the reduced form effect of $E X T I M E_{i j}$ on three post-application labor supply outcomes: labor force participation (defined as annual earnings $>\$ 1,000$ ), substantial gainful activity (defined as annual earnings $>$ annualized SGA), and annual earnings. Each labor supply outcome is evaluated 2, 3, and 4 years after the initial decision in 2005, corresponding to calendar years 2007, 2008, and 2009, respectively. Reduced form models are of interest because they provide causal estimates without the need to specify exact causal channels.

Table 5 presents the reduced form coefficients on $E X T I M E_{i j}$ estimated over the full sample. In Panel A, a one-month increase in examiner processing time reduces the probability of labor force participation 2 years after the initial decision by -0.005 ( $1 / 2$ of a percentage point). The effect is the same at 3 years. The somewhat smaller effect at 4 years is likely due to weak employment conditions in 2009. All of the coefficients are precisely estimated and statistically different from zero. In Panel B, a one-month increase in examiner processing time reduces the probability of engaging in substantial gainful activity 2 years after the initial decision by -0.0019 (also statistically significant). The effect is similar at 3 and 4 years. In Panel C, a one-month increase in examiner processing time leads to a $\$ 75$ reduction in annual earnings 2 years after the 
initial decision; the effect declines slightly at 3 and 4 years, but the coefficients are not statistically different from one another.

Table 6 presents reduced form coefficients on $\operatorname{EXTIME}_{i j}$ estimated for the initially allowed and initially denied samples. In the allowed sample, a one-month increase in examiner processing time reduces the probability of labor force participation 2 years after the initial decision by -0.003 (about $1 / 3$ of a percentage point). The effect is similar at 3 and 4 years. The reduced form effects of examiner processing time on substantial gainful activity and on earnings are mostly imprecisely estimated. The effects are uniformly larger in the initially denied sample; this is because as noted earlier in Section 3, the reduced form effect of EXTIME $E_{i j}$ in a sample in which appeals are possible encompasses both its direct effect of labor supply and its indirect effect on ultimate benefit receipt operating through the appellate channel. In the initially denied sample, a one-month increase in examiner processing time leads to a larger -0.006 reduction in the probability of labor force participation at 2 years, a -0.0028 reduction in the probability of substantial gainful activity at 2 years, and a $\$ 100$ reduction in annual earnings at 2 years after the initial decision. The effects at 3 and 4 years after the initial decision are of similar magnitude.

Table 7 shows these same reduced form relationships separately for applicants in nonprototype and prototype states. Since non-prototype states comprise three-quarters of the full sample, the estimates are similar to those reported in Table 5. However, the reduced form estimates for the prototype states are uniformly larger. This is suggestive of a larger indirect "appeals effect" of examiner processing time on labor supply (coming from increased benefit receipt) in prototype states than in non-prototype states. This is because, as we will show in Table 8, EXTIME $E_{i j}$ exerts a stronger effect on benefit receipt in prototype states than in nonprototype states. 


\subsection{Conditional Pathways}

As described above, the reduced form effect of $E X T I M E_{i j}$ on labor supply outcomes encompasses both a direct effect on applicant processing time and an indirect effect through the channel of the appeals process, which affects ultimate benefit receipt. In Table 8, we investigate these relationships by examining the effect of $E X T I M E_{i j}$ on conditional waiting times and pathways through the disability determination process, separately for non-prototype and prototype states. Each row represents a regression on a different outcome: cumulative time from filing to decision at a given administrative level, conditional on participation at that level; probability of appeal, conditional on denial at the previous level; and probability of denial at a given administrative level, conditional on participation at that level. The last two rows in each panel provide estimates encompassing the cumulative effects of $E X T I M E_{i j}$ on final processing time (time to last observed decision in our data set) and SSDI benefit receipt among all applicants. Each regression contains the full set of controls and computes standard errors clustered on DDS examiner.

In both non-prototype and prototype states, $E X T I M E_{i j}$ has almost a one-for-one impact on initial processing time; that is, a one-month increase in the examiner's average time increases applicants' initial processing times (at the DDS level) by almost one month. Importantly for our analysis below, EXTIME $E_{i j}$ is shown to have no effect on the probability of initial denial; in other words, slow examiners are no more likely to be lenient or strict than fast examiners.

However, being denied by a slow examiner does make one more likely to appeal to the next level (reconsideration in the non-prototype states or ALJ in the prototype states). This may be because applicants' opportunity cost of appealing has been reduced by the longer initial 
processing time, through its impact on prospective employment, or it could be because applicants infer something about their chances of prevailing upon appeal given the initial examiner's tardiness. In any case, this higher likelihood of appeal directly translates into a higher probability of benefit receipt, and a longer final processing time. Assignment to an examiner who is one month slower on average yields a statistically significant increase in the probability of benefit receipt of 0.31 percentage points $(0.5 \%)$ in a non-prototype state and 0.56 percentage points $(0.8 \%)$ in a prototype state. As a result, we confine our IV analysis to applicants who were initially allowed in 2005, since EXTIME $E_{i j}$ is uncorrelated with the initial allowance decision, which equals the final allowance decision in this case.

\subsection{OLS and IV Estimates of the Effect of Time to Decision on Labor Supply Outcomes}

In Table 9, we show OLS and IV estimates of the effect of time to final decision on labor supply outcomes evaluated 2, 3, and 4 years after the initial decision in 2005 . In all cases, the estimates are for the initially allowed sample only, since as noted above, this is the only sample in which we can recover the pure direct effect of processing time. As expected, the OLS estimates are uniformly smaller than the IV estimates. Our IV estimates of the effect of a onemonth increase in time until final decision on labor force participation are -0.003692 years after the initial decision. The IV estimate rises slightly at 3 years after the initial decision $(-0.00471)$ and falls slightly at 4 years $(-0.00323)$, but the coefficients are not statistically different. The IV estimates for the substantial gainful activity and earnings outcomes are imprecisely estimated, though similar in magnitude to the reduced form coefficients in Table 6.

As described in Section 3, our IV estimate is an estimate of the employment decay rate, $\delta$. Multiplying the decay rate by average processing times for SSDI applicants gives an estimate 
of the average labor supply decay effect. Among all applicants, for whom the average processing time is 12.7 months, we estimate an average decay in post-application employment of 4.4 percentage points (16\%). The decay effect is notably larger for applicants who pursue an appeal. Regardless of the ultimate decision, applicants who are denied in the initial determination phase and who pursue appeals are, on average, 7.6 percentage points less likely to work 2 years after the initial determination compared to applicants who do not pursue appeals. This highlights the appeals process as a particularly costly avenue for obtaining SSDI benefits.

\section{Conclusion}

A well-known body of research explores how the award of SSDI benefits affects the labor supply and earnings of recipients. In this paper we explore a complementary — and we believe equally consequential—question: how do long application processing time, during which applicants are effectively barred from earning more than $\$ 1,000$ per month, affect the subsequent employment of denied applicants and SSDI beneficiaries? Our approach exploits exogenous variation in average processing time by disability examiners as an instrument for applicant waiting time. Using a unique administrative workload database, we evaluate how the substantial time spent out of the labor market during the application and appeals process - more than one year on average, across all applicants - affects subsequent employment opportunities and earnings of both allowed and denied applicants.

We find that longer processing times significantly reduce the employment and earnings of SSDI applicants in the years after their initial decision. Our main estimates indicate that a one standard deviation (2.4 months) increase in initial processing time reduces annual employment rates by about 1 percentage point (3.2\%) in the years following the initial determination. 
Extrapolating these effects to total applicant processing times, we estimate that the SSDI determination process directly reduces the post-application employment of denied applicants by approximately 3.6 percentage points (7\%) and allowed applicants by approximately 5.2 percentage points $(33 \%)$.

The literature to date has been exclusively focused on estimating the causal effect of benefit receipt on labor supply outcomes. Importantly, this paper presents the first causal estimates of the labor supply decay effect, which is an additional cost of the SSDI determination process. We show that the decay effect is a distinct causal channel through which the SSDI program impacts post-application labor supply outcomes. Combining the labor supply decay effect (4.4 percentage points for the average applicant) with a credible estimate of the benefit receipt effect (e.g., 18 percentage points as reported in MMS 2011) suggests that the SSDI program effect on employment is nearly 25 percent larger than previously thought. 


\section{References}

Bound, John (1989) "The Health and Earnings of Rejected Disability Insurance Applicants." American Economic Review, 79(3), pp. 482-503.

Bound, John (1991). "The Health and Earnings of Rejected Disability Insurance Applicants: Reply." American Economic Review, 81(5), pp. 1427-1434.

Chen, Susan and Wilbert van der Klaauw (2008). "The Work Disincentive Effects of the Disability Insurance Program in the 1990s.” Journal of Econometrics, 142, pp. 757-784.

French, Eric and Jae Song (2009). "The Effect of Disability Insurance Receipt on Labor Supply." Federal Reserve Bank of Chicago Working Paper Series, WP 2009-05.

Maestas, Nicole, Kathleen Mullen and Alexander Strand (2011). "Does Disability Insurance Receipt Discourage Work? Using Examiner Assignment to Estimate Causal Effects of SSDI Receipt," MRRC Working Paper 2010-241, May 2011.

Office of the Inspector General (2008). "Disability Claims Overall Processing Times." Audit Report A-01-08-18011.

Parsons, Donald (1991). "The Health and Earnings of Rejected Disability Insurance Applicants: Comment." American Economic Review, 81(5), pp. 1419.1426.

Social Security Advisory Board (2006). "Disability Decision Making: Data and Materials." Washington, DC (available at www.ssab.gov).

von Wachter, Till, Jae Song and Joyce Manchester (2010). "Trends in Employment and Earnings of Allowed and Rejected Applicants to the Social Security Disability Insurance Program." Forthcoming, American Economic Review. 


\begin{tabular}{|c|c|c|c|c|c|c|c|}
\hline Variable & All & $\begin{array}{c}\text { Non- } \\
\text { Prototype }\end{array}$ & Prototype & $\begin{array}{l}\text { Initially } \\
\text { Allowed }\end{array}$ & $\begin{array}{l}\text { Initially } \\
\text { Denied }\end{array}$ & $\begin{array}{c}\text { Finally } \\
\text { Allowed }\end{array}$ & $\begin{array}{l}\text { Finally } \\
\text { Denied }\end{array}$ \\
\hline$\%$ of sample & $100.0 \%$ & $75.1 \%$ & $24.9 \%$ & $33.1 \%$ & $66.9 \%$ & $66.7 \%$ & $33.3 \%$ \\
\hline Examiner processing time (EXTIME) & $\begin{array}{c}2.9 \\
(0.8)\end{array}$ & $\begin{array}{c}2.9 \\
(0.8)\end{array}$ & $\begin{array}{c}2.7 \\
(0.7)\end{array}$ & $\begin{array}{c}2.8 \\
(0.8)\end{array}$ & $\begin{array}{c}2.9 \\
(0.8)\end{array}$ & $\begin{array}{c}2.9 \\
(0.8)\end{array}$ & $\begin{array}{c}2.8 \\
(0.8)\end{array}$ \\
\hline Initial allowance rate & $33.1 \%$ & $32.6 \%$ & $34.9 \%$ & $100.0 \%$ & $0.0 \%$ & $49.6 \%$ & $0.0 \%$ \\
\hline Appeal (recon or AL) | initial denial & $59.7 \%$ & $61.1 \%$ & $55.1 \%$ & $0.0 \%$ & $59.7 \%$ & $88.2 \%$ & $30.8 \%$ \\
\hline Appeal allowance rate | appeal & $69.6 \%$ & $66.1 \%$ & $81.6 \%$ & -- & $69.6 \%$ & $93.7 \%$ & $0.0 \%$ \\
\hline DI Beneficiary by 2010 & $66.7 \%$ & $66.0 \%$ & $71.4 \%$ & $100.0 \%$ & $54.8 \%$ & $100.0 \%$ & $0.0 \%$ \\
\hline Concurrent claim & $51.2 \%$ & $51.8 \%$ & $49.5 \%$ & $40.8 \%$ & $56.4 \%$ & $45.9 \%$ & $61.8 \%$ \\
\hline Terminal illness & $0.8 \%$ & $0.8 \%$ & $0.8 \%$ & $2.0 \%$ & $0.2 \%$ & $1.1 \%$ & $0.2 \%$ \\
\hline Age & $\begin{array}{c}46.7 \\
(11.0)\end{array}$ & $\begin{array}{c}46.7 \\
(11.0)\end{array}$ & $\begin{array}{c}46.4 \\
(11.1)\end{array}$ & $\begin{array}{c}50.4 \\
(10.8)\end{array}$ & $\begin{array}{c}44.8 \\
(10.6)\end{array}$ & $\begin{array}{c}48.7 \\
(10.2)\end{array}$ & $\begin{array}{c}42.6 \\
(11.4)\end{array}$ \\
\hline \multicolumn{8}{|l|}{ Earnings (2008\$) } \\
\hline $3-5$ years prior & $\begin{array}{c}22,729 \\
(27,867)\end{array}$ & $\begin{array}{c}22,330 \\
(27,861)\end{array}$ & $\begin{array}{c}23,931 \\
(27,850)\end{array}$ & $\begin{array}{c}28,890 \\
(34,087)\end{array}$ & $\begin{array}{c}19,676 \\
(23,612)\end{array}$ & $\begin{array}{c}26,140 \\
(29,892)\end{array}$ & $\begin{array}{c}15,885 \\
(21,718)\end{array}$ \\
\hline 2 years later & $\begin{array}{c}4,319 \\
(12,529)\end{array}$ & $\begin{array}{c}4,337 \\
(12,758)\end{array}$ & $\begin{array}{c}4,266 \\
(11,809)\end{array}$ & $\begin{array}{c}1,947 \\
(12,356)\end{array}$ & $\begin{array}{c}5,494 \\
(12,447)\end{array}$ & $\begin{array}{c}2,037 \\
(10,581)\end{array}$ & $\begin{array}{c}8,897 \\
(14,693)\end{array}$ \\
\hline 3 years later & $\begin{array}{c}4,293 \\
(11,843)\end{array}$ & $\begin{array}{c}4,295 \\
(11,757)\end{array}$ & $\begin{array}{c}4,287 \\
(12,098)\end{array}$ & $\begin{array}{c}1,960 \\
(9,964)\end{array}$ & $\begin{array}{c}5,424 \\
(12,498)\end{array}$ & $\begin{array}{c}1,829 \\
(8,760)\end{array}$ & $\begin{array}{c}9,164 \\
(15,169)\end{array}$ \\
\hline 4 years later & $\begin{array}{c}3,924 \\
(12,001)\end{array}$ & $\begin{array}{c}3,915 \\
(12,134)\end{array}$ & $\begin{array}{c}3,951 \\
(11,592)\end{array}$ & $\begin{array}{c}1,866 \\
(11,670)\end{array}$ & $\begin{array}{c}4,898 \\
(12,032)\end{array}$ & $\begin{array}{c}1,572 \\
(9,516)\end{array}$ & $\begin{array}{c}8,485 \\
(14,703)\end{array}$ \\
\hline \multicolumn{8}{|l|}{ Employed (earning more than $\$ 1,000$ ) } \\
\hline 2 years later & $27.8 \%$ & $28.1 \%$ & $26.9 \%$ & $13.8 \%$ & $34.8 \%$ & $15.5 \%$ & $52.4 \%$ \\
\hline 3 years later & $26.4 \%$ & $26.5 \%$ & $25.9 \%$ & $13.4 \%$ & $32.7 \%$ & $13.6 \%$ & $51.7 \%$ \\
\hline \multicolumn{8}{|c|}{$\begin{array}{l}\text { Performing SGA (earning more than real } \\
\text { SGA threshold) }\end{array}$} \\
\hline 2 years later & $13.3 \%$ & $13.5 \%$ & $12.7 \%$ & $4.5 \%$ & $17.6 \%$ & $5.3 \%$ & $29.3 \%$ \\
\hline 3 years later & $13.2 \%$ & $13.3 \%$ & $12.9 \%$ & $4.6 \%$ & $17.4 \%$ & $4.6 \%$ & $30.1 \%$ \\
\hline 4 years later & $11.6 \%$ & $11.6 \%$ & $11.4 \%$ & $4.1 \%$ & $15.1 \%$ & $3.6 \%$ & $27.0 \%$ \\
\hline$n$ & $1,128,388$ & 847,221 & 281,167 & 373,851 & 754,537 & 753,038 & 375,350 \\
\hline
\end{tabular}




\begin{tabular}{|c|c|c|c|c|c|c|c|c|c|c|}
\hline \multicolumn{11}{|c|}{ A. Cumulative Processing Times, by Administrative Level } \\
\hline & \multicolumn{5}{|c|}{ Non-Prototype States } & \multicolumn{5}{|c|}{ Prototype States } \\
\hline & $\%$ Cases & Mean & Std. Dev. & 50th Perc. & 90th Perc. & $\%$ Cases & Mean & Std. Dev. & 50th Perc. & 90th Perc. \\
\hline Time to Initial Decision & 100.0 & 3.9 & 2.4 & 3.4 & 6.4 & 100.0 & 3.6 & 2.2 & 3.3 & 5.9 \\
\hline Time to Reconsideration Decision & 36.3 & 8.9 & 4.0 & 8.1 & 14.1 & -- & -- & -- & -- & -- \\
\hline Time to ALJ Decision & 28.7 & 32.6 & 15.2 & 29.6 & 56.3 & 35.6 & 28.7 & 15.7 & 25.4 & 53.7 \\
\hline Time to Higher Appeals Decision* & 1.7 & 47.5 & 11.9 & 47.4 & 63.4 & 0.7 & 44.5 & 12.8 & 43.5 & 62.1 \\
\hline Time to Reapplication Decision* & 2.6 & 32.7 & 17.3 & 31.1 & 59.0 & 2.6 & 33.6 & 16.8 & 31.3 & 59.5 \\
\hline Time to Last Observed Decision & 100.0 & 12.7 & 15.2 & 5.4 & 35.2 & 100.0 & 12.6 & 15.3 & 4.7 & 33.6 \\
\hline \multicolumn{11}{|l|}{ B. Time at DDS, by Stept } \\
\hline & \multicolumn{5}{|c|}{ Non-Prototype States } & \multicolumn{5}{|c|}{ Prototype States } \\
\hline & \% Cases & Mean & Std. Dev. & 50th Perc. & 90th Perc. & \% Cases & Mean & Std. Dev. & 50th Perc. & 90th Perc. \\
\hline All & 100.0 & 3.0 & 2.2 & 2.7 & 5.2 & 100.0 & 2.8 & 1.6 & 2.5 & 4.8 \\
\hline Denied: Impairment not severe & 18.0 & 2.7 & 1.6 & 2.3 & 4.7 & 14.4 & 2.5 & 1.4 & 2.2 & 4.4 \\
\hline Allowed: Meets the listings & 14.7 & 2.5 & 1.8 & 2.2 & 4.9 & 13.4 & 2.3 & 1.7 & 1.9 & 4.5 \\
\hline Denied: Capacity for past work & 25.0 & 3.1 & 1.6 & 2.9 & 5.3 & 21.4 & 2.9 & 1.5 & 2.7 & 4.8 \\
\hline Allowed/Denied: Other Capacity & 42.4 & 3.2 & 1.8 & 2.9 & 5.4 & 50.8 & 2.9 & 1.5 & 2.7 & 4.9 \\
\hline
\end{tabular}

Notes: ${ }^{*}$ indicates we only observe time to decision at these stages if the final decision is allowance

† Technical denials are excluded from our sample. 


\begin{tabular}{|c|c|c|c|c|}
\hline & Initially Allowed & $\begin{array}{c}\text { Allowed on Appeal } \\
\text { or Reapplication }\end{array}$ & $\begin{array}{c}\text { Initially Denied, No } \\
\text { Appeal } \\
\end{array}$ & $\begin{array}{l}\text { Initially Denied, } \\
\text { Denied on Appeal }\end{array}$ \\
\hline No. observations & 373,851 & 379,187 & 259,652 & 115,698 \\
\hline Percentage & $33.1 \%$ & $33.6 \%$ & $23.0 \%$ & $10.3 \%$ \\
\hline Time at DDS & 2.8 & 3.1 & 2.8 & 2.9 \\
\hline & $(1.8)$ & $(1.6)$ & $(1.6)$ & $(1.6)$ \\
\hline Total Processing Time & 3.8 & 24.3 & $3.7^{c}$ & $23.2^{c}$ \\
\hline & (2.7) & $(16.3)$ & $(2.2)$ & $(19.2)$ \\
\hline Total Processing Time, Pooled & \multicolumn{2}{|c|}{14.1} & \multicolumn{2}{|c|}{$9.7^{c}$} \\
\hline
\end{tabular}

Notes: Standard deviations in parentheses. ${ }^{\mathrm{C}}$ denotes censored due to unobserved higher level appeals and/or reapplications. 


\begin{tabular}{|c|c|c|c|c|c|}
\hline & All & $\begin{array}{l}\text { Initially } \\
\text { Allowed }\end{array}$ & $\begin{array}{l}\text { Initially } \\
\text { Denied }\end{array}$ & $\begin{array}{c}\text { Non- } \\
\text { Prototype }\end{array}$ & Prototype \\
\hline \multirow[t]{2}{*}{ EXTIME } & $1.471 * * *$ & $0.906 * * *$ & $1.574 * * *$ & $1.616^{* * *}$ & $0.821 * * *$ \\
\hline & -0.0454 & -0.0103 & -0.0423 & -0.0503 & -0.108 \\
\hline $\mathrm{R}^{\wedge} 2$ & 0.006 & 0.072 & 0.006 & 0.008 & 0.001 \\
\hline \multirow[t]{2}{*}{ Plus assignment variables } & $0.986 * * *$ & $0.847^{* * *}$ & $1.062 * * *$ & $1.027^{* * *}$ & $0.832 * * *$ \\
\hline & $(0.02870)$ & $(0.01190)$ & $(0.03440)$ & $(0.03180)$ & $(0.06640)$ \\
\hline $\mathrm{R}^{\wedge} 2$ & 0.047 & 0.119 & 0.027 & 0.051 & 0.037 \\
\hline \multirow[t]{2}{*}{ Plus individual characteristics } & $0.966 * * *$ & $0.840 * * *$ & $1.031 * * *$ & $0.988 * * *$ & $0.907 * * *$ \\
\hline & $(0.0267)$ & $(0.0117)$ & $(0.0335)$ & $(0.0293)$ & $(0.0649)$ \\
\hline $\mathrm{R}^{\wedge} 2$ & 0.1 & 0.132 & 0.064 & 0.103 & 0.097 \\
\hline No. observations & $1,128,388$ & 373,851 & 754,537 & 847,221 & 281,167 \\
\hline
\end{tabular}


Table 5. Reduced Form Regressions: Effect of EXTIME on Labor Supply Outcomes

2 Years Later 3 Years Later 4 Years Later

(2007)

(2008)

(2009)

\begin{tabular}{lccc}
\hline A. Dependent Variable $=$ Earn $>=\$ \mathbf{1 , 0 0 0 / Y e a r ~}$ & & \\
\hline EXTIME & $-0.00502^{* * *}$ & $-0.00523^{* * *}$ & $-0.00367^{* * *}$ \\
& $(0.000740)$ & $(0.000732)$ & $(0.000713)$ \\
$\mathrm{R}^{\wedge} 2$ & 0.086 & 0.088 & 0.079 \\
\hline B. Dependent Variable = Earn $>=$ SGA & & & \\
\hline EXTIME & $-0.00191^{* * *}$ & $-0.00212^{* * *}$ & $-0.00172^{* * *}$ \\
& $(0.000555)$ & $(0.000579)$ & $(0.000539)$ \\
$\mathrm{R}^{\wedge} 2$ & 0.049 & 0.054 & 0.05 \\
\hline C. Dependent Variable = Earnings & & & \\
\hline EXTIME & $-75.16^{* * *}$ & $-68.86^{* * *}$ & $-54.45^{* *}$ \\
& $(22.57)$ & $(21.06)$ & $(22.09)$ \\
$\mathrm{R}^{\wedge} 2$ & 0.065 & 0.062 & 0.054 \\
\hline No. observations & & & $1,079,575$ \\
\hline
\end{tabular}




\begin{tabular}{|c|c|c|c|c|c|c|}
\hline & \multicolumn{3}{|c|}{ Initially Allowed } & \multicolumn{3}{|c|}{ Initially Denied } \\
\hline & $\begin{array}{c}2 \text { Years Later } \\
(2007)\end{array}$ & $\begin{array}{c}3 \text { Years Later } \\
(2008)\end{array}$ & $\begin{array}{c}4 \text { Years Later } \\
\text { (2009) }\end{array}$ & $\begin{array}{c}2 \text { Years Later } \\
\text { (2007) }\end{array}$ & $\begin{array}{c}3 \text { Years Later } \\
(2008)\end{array}$ & $\begin{array}{c}4 \text { Years Later } \\
\text { (2009) }\end{array}$ \\
\hline \multicolumn{7}{|c|}{ A. Dependent Variable = Earn $>=\$ 1,000 /$ Year } \\
\hline EXTIME & $\begin{array}{c}-0.00310 * * * \\
(0.000974)\end{array}$ & $\begin{array}{c}-0.00398 * * * \\
(0.000965)\end{array}$ & $\begin{array}{c}-0.00273 * * * \\
(0.000917)\end{array}$ & $\begin{array}{c}-0.00616 * * * \\
(0.000946)\end{array}$ & $\begin{array}{c}-0.00583^{* * *} \\
(0.000934)\end{array}$ & $\begin{array}{c}-0.00408 * * * \\
(0.000903)\end{array}$ \\
\hline$R^{\wedge} 2$ & 0.057 & 0.061 & 0.057 & 0.079 & 0.081 & 0.074 \\
\hline \multicolumn{7}{|c|}{ B. Dependent Variable = Earn $>=$ SGA } \\
\hline EXTIME & $\begin{array}{l}-8.51 \mathrm{E}-04 \\
(0.000602)\end{array}$ & $\begin{array}{l}-0.00110^{*} \\
(0.000573)\end{array}$ & $\begin{array}{l}-0.000953^{*} \\
(0.000562)\end{array}$ & $\begin{array}{c}-0.00280^{* * *} \\
(0.000753)\end{array}$ & $\begin{array}{c}-0.00282^{* * *} \\
(0.000776)\end{array}$ & $\begin{array}{c}-0.00223^{* * *} \\
(0.000709)\end{array}$ \\
\hline $\mathrm{R}^{\wedge} 2$ & 0.038 & 0.04 & 0.04 & 0.046 & 0.051 & 0.048 \\
\hline \multicolumn{7}{|c|}{ C. Dependent Variable = Earnings } \\
\hline EXTIME & $\begin{array}{l}-49.58 \\
(37.29)\end{array}$ & $\begin{array}{c}-70.56^{* *} \\
(29.36)\end{array}$ & $\begin{array}{c}-17.6 \\
(38.52)\end{array}$ & $\begin{array}{c}-100.2^{* * *} \\
(25.95)\end{array}$ & $\begin{array}{c}-74.95^{* * *} \\
(26.03)\end{array}$ & $\begin{array}{c}-77.25 * * * \\
(24.29)\end{array}$ \\
\hline$R^{\wedge} 2$ & 0.044 & 0.045 & 0.032 & 0.084 & 0.073 & 0.07 \\
\hline No. observations & 373,851 & 361,625 & 346,848 & 754,537 & 745,489 & 732,727 \\
\hline
\end{tabular}




\begin{tabular}{|c|c|c|c|c|c|c|}
\hline & \multicolumn{3}{|c|}{ Non-Prototype } & \multicolumn{3}{|c|}{ Prototype } \\
\hline & $\begin{array}{c}2 \text { Years Later } \\
\text { (2007) }\end{array}$ & $\begin{array}{c}3 \text { Years Later } \\
(2008)\end{array}$ & $\begin{array}{c}4 \text { Years Later } \\
\text { (2009) }\end{array}$ & $\begin{array}{l}2 \text { Years Later } \\
\text { (2007) }\end{array}$ & $\begin{array}{c}3 \text { Years Later } \\
\text { (2008) }\end{array}$ & $\begin{array}{c}4 \text { Years Later } \\
\text { (2009) }\end{array}$ \\
\hline \multicolumn{7}{|c|}{ A. Dependent Variable = Earn $>=\$ 1,000 /$ Year } \\
\hline EXTIME & $\begin{array}{c}-0.00478^{* * *} \\
(0.000821)\end{array}$ & $\begin{array}{c}-0.00460 * * * \\
(0.000815)\end{array}$ & $\begin{array}{c}-0.00294^{* * *} \\
(0.000780)\end{array}$ & $\begin{array}{c}-0.00612^{* * *} \\
(0.001730)\end{array}$ & $\begin{array}{c}-0.00797^{* * *} \\
(0.001670)\end{array}$ & $\begin{array}{c}-0.00665^{* * *} \\
(0.001750)\end{array}$ \\
\hline $\mathrm{R}^{\wedge} 2$ & 0.086 & 0.089 & 0.079 & 0.085 & 0.088 & 0.081 \\
\hline \multicolumn{7}{|c|}{ B. Dependent Variable $=$ Earn $>=$ SGA } \\
\hline EXTIME & $\begin{array}{l}-0.00136^{* *} \\
(0.000611)\end{array}$ & $\begin{array}{c}-0.00172 * * * \\
(0.000635)\end{array}$ & $\begin{array}{l}-0.00108^{*} \\
(0.000596)\end{array}$ & $\begin{array}{c}-0.00419 * * * \\
(0.001330)\end{array}$ & $\begin{array}{c}-0.00376^{* * *} \\
(0.001400)\end{array}$ & $\begin{array}{c}-0.00437 * * * \\
(0.001270)\end{array}$ \\
\hline$R^{\wedge} 2$ & 0.049 & 0.054 & 0.05 & 0.049 & 0.055 & 0.053 \\
\hline \multicolumn{7}{|c|}{ C. Dependent Variable $=$ Earnings } \\
\hline EXTIME & $\begin{array}{c}-55.31 * * \\
(25.39)\end{array}$ & $\begin{array}{c}-53.69 * * \\
(23.39)\end{array}$ & $\begin{array}{l}-31.83 \\
(25.06)\end{array}$ & $\begin{array}{c}-159.1^{* * *} \\
(48.10)\end{array}$ & $\begin{array}{c}-131.6^{* * *} \\
(48.85)\end{array}$ & $\begin{array}{c}-149.4^{* * *} \\
(47.03)\end{array}$ \\
\hline $\mathrm{R}^{\wedge} 2$ & 0.064 & 0.062 & 0.053 & 0.072 & 0.063 & 0.063 \\
\hline No. observations & 847,221 & 830,884 & 809,855 & 281,167 & 276,230 & 269,720 \\
\hline
\end{tabular}




\begin{tabular}{|c|c|c|c|c|c|}
\hline Outcome & $\mathbf{N}$ & $\begin{array}{c}\text { Mean } \\
\text { Dep. Var. }\end{array}$ & $\begin{array}{l}\text { Coeff. on } \\
\text { EXTIME }\end{array}$ & Std. Error & $\mathbf{R}^{\wedge} \mathbf{2}$ \\
\hline \multicolumn{6}{|l|}{ A. Non-Prototype States } \\
\hline Time to Initial Decision & 847,221 & 3.901 & $0.895^{* * *}$ & $(0.009)$ & 0.149 \\
\hline Initial Denial & 847,221 & 0.674 & 0.00223 & $(0.001)$ & 0.204 \\
\hline Appeal to Recon. I Initial Denial & 571,413 & 0.538 & $0.00266^{*}$ & $(0.001)$ & 0.064 \\
\hline Time to Recon. Decision I Appeal to Recon. & 307,446 & 8.943 & $0.904 * * *$ & $(0.013)$ & 0.143 \\
\hline Recon. Denial | Appeal to Recon. & 307,446 & 0.889 & $-0.00151^{*}$ & $(0.001)$ & 0.054 \\
\hline Appeal to ALJ | Recon. Denial & 273,260 & 0.73 & $0.00551 * * *$ & $(0.001)$ & 0.064 \\
\hline Time to ALJ Decision | Appeal to ALJ & 242,733 & 32.57 & $0.822 * * *$ & $(0.048)$ & 0.145 \\
\hline ALJ Denial | Appealed to ALJ & 242,733 & 0.184 & $-0.00251^{* *}$ & $(0.001)$ & 0.069 \\
\hline Time to Higher Appeal Decision | Higher Appeal† & 4,777 & 47.55 & $1.391 * * *$ & $(0.332)$ & 0.233 \\
\hline Time to Reapplication Decision | Reapplication ${ }^{\dagger}$ & 21,955 & 30.38 & $0.734 * * *$ & $(0.168)$ & 0.360 \\
\hline Time to Last Observed Decision & 847,221 & 12.73 & $0.988 * * *$ & $(0.029)$ & 0.103 \\
\hline Receive Benefit & 847,221 & 0.66 & $0.00308 * * *$ & $(0.001)$ & 0.127 \\
\hline \multicolumn{6}{|l|}{ B. Prototype States } \\
\hline Time to Initial Decision & 281,167 & 3.632 & $0.886 * * *$ & $(0.010)$ & 0.117 \\
\hline Initial Denial & 281,167 & 0.651 & -0.00307 & $(0.003)$ & 0.212 \\
\hline Appeal to ALJ | Initial Denial & 183,124 & 0.547 & $0.0100 * * *$ & $(0.002)$ & 0.086 \\
\hline Time to ALJ Decision | Appeal to ALJ & 100,112 & 28.67 & $0.725^{* * *}$ & $(0.098)$ & 0.147 \\
\hline ALJ Denial | Appealed to ALJ & 100,112 & 0.179 & -0.00163 & $(0.002)$ & 0.070 \\
\hline Time to Higher Appeal Decision | Higher Appeal† & 1,901 & 44.51 & 0.356 & $(0.605)$ & 0.233 \\
\hline Time to Reapplication Decision | Reapplication† & 7,189 & 29.48 & -0.0812 & $(0.340)$ & 0.375 \\
\hline Time to Last Observed Decision & 281,167 & 12.57 & $0.907 * * *$ & $(0.065)$ & 0.097 \\
\hline Receive Benefit & 281,167 & 0.69 & $0.00560 * * *$ & $(0.002)$ & 0.134 \\
\hline
\end{tabular}

Notes: $\dagger=$ ultimate allowances only 


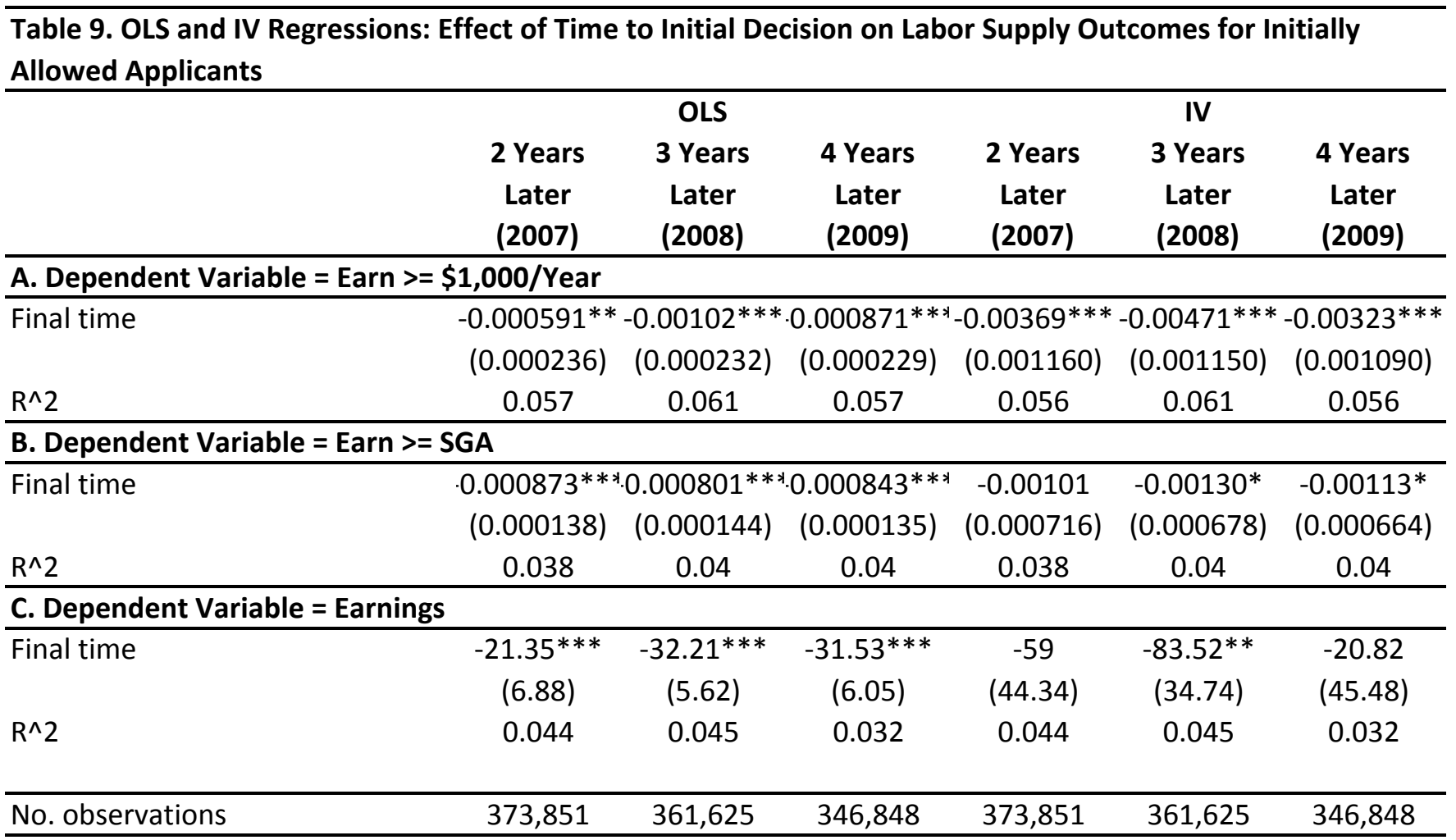


Appendix Table 1. Percentage of Claimants Initially Denied in 2005 Receiving SSDI Benefits, by Year

... with no Reconsideration or

Initial Denials... . ... also Denied in an AL Hearing AL Hearing

$\begin{array}{lll}\mathrm{N}= & 62,660 & 304,425\end{array}$

\begin{tabular}{ccc}
\hline Year & Cumulative Percentage & Cumulative Percentage \\
\hline 2005 & 0.2 & 1.0 \\
2006 & 0.8 & 4.4 \\
2007 & 3.0 & 8.0 \\
2008 & 6.6 & 10.8 \\
2009 & 10.0 & 13.0 \\
2010 & 12.5 & 14.7 \\
\hline
\end{tabular}




\begin{tabular}{l|c|cc}
\hline \multicolumn{4}{|l|}{ Appendix Table 2. Summary Statistics for DDS Examiners } \\
\hline $\begin{array}{l}\text { Average processing time for decisions } \\
\text { made in 2005, months }\end{array}$ & All & Non-Prototype & Prototype \\
\hline & 3.0 & 3.1 & 2.8 \\
Mean & $(1.0)$ & $(1.1)$ & $(0.8)$ \\
& & & \\
10th percentile & 2.0 & 2.0 & 1.9 \\
25th percentile & 2.4 & 2.4 & 2.3 \\
Median & 2.8 & 2.9 & 2.7 \\
75th percentile & 3.4 & 3.5 & 3.2 \\
90th percentile & 4.2 & 4.3 & 3.7 \\
& & & \\
$\mathrm{n}$ & 8,769 & 6,723 & 2,046 \\
\hline
\end{tabular}

Note: Standard deviations in parentheses. 


\section{Figure 1. Five-Step Review Process}

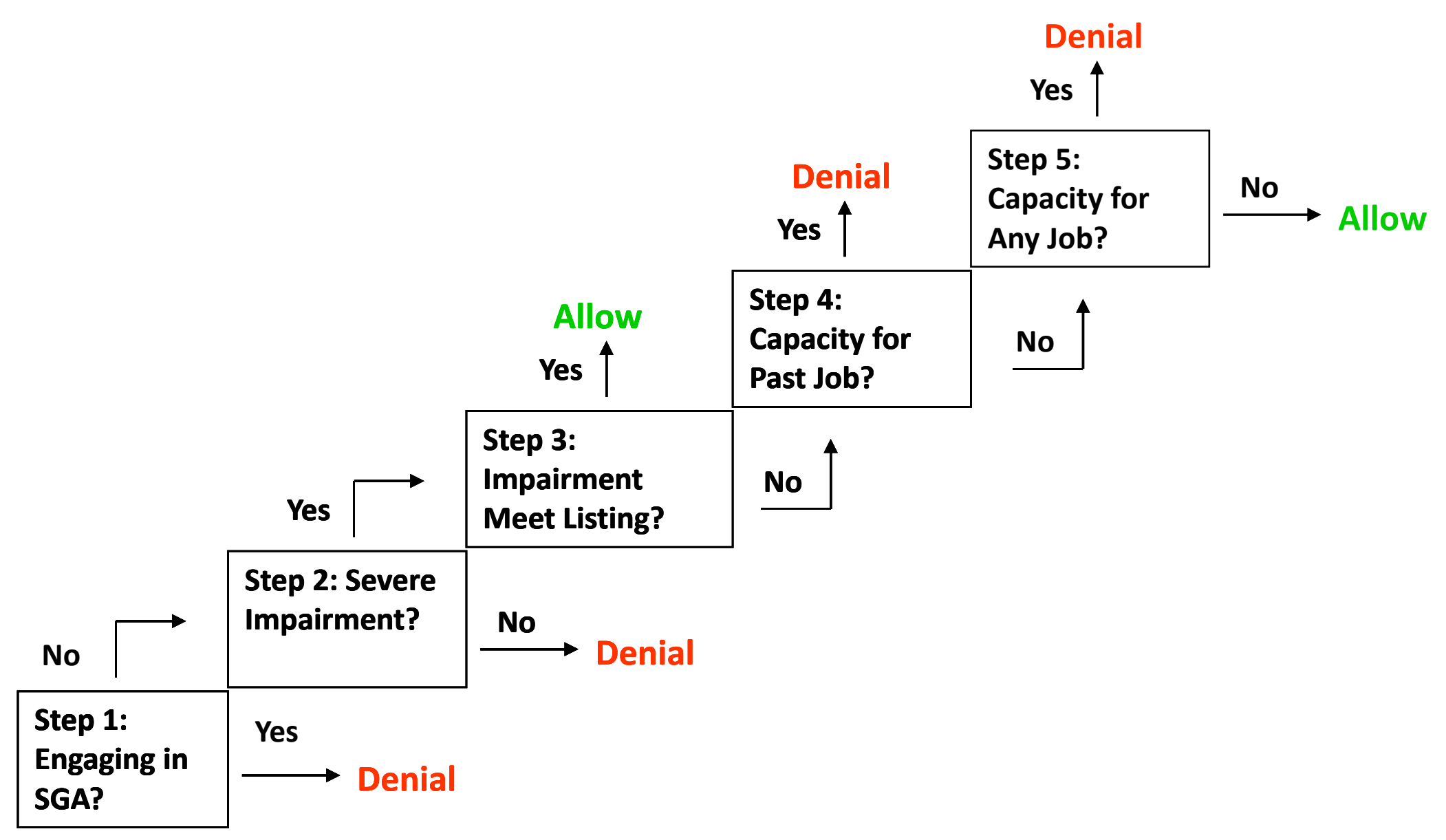




\section{Figure 2. Initial and Appeals Process}

\section{Non-Prototype States}

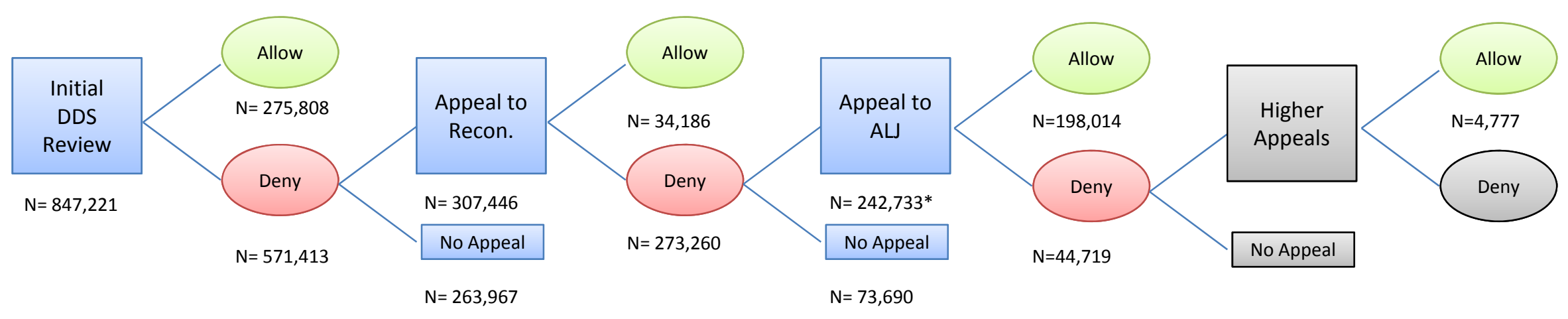

* Some ALJ appeals are observed without an observed reconsideration appeal.

\section{Prototype States}

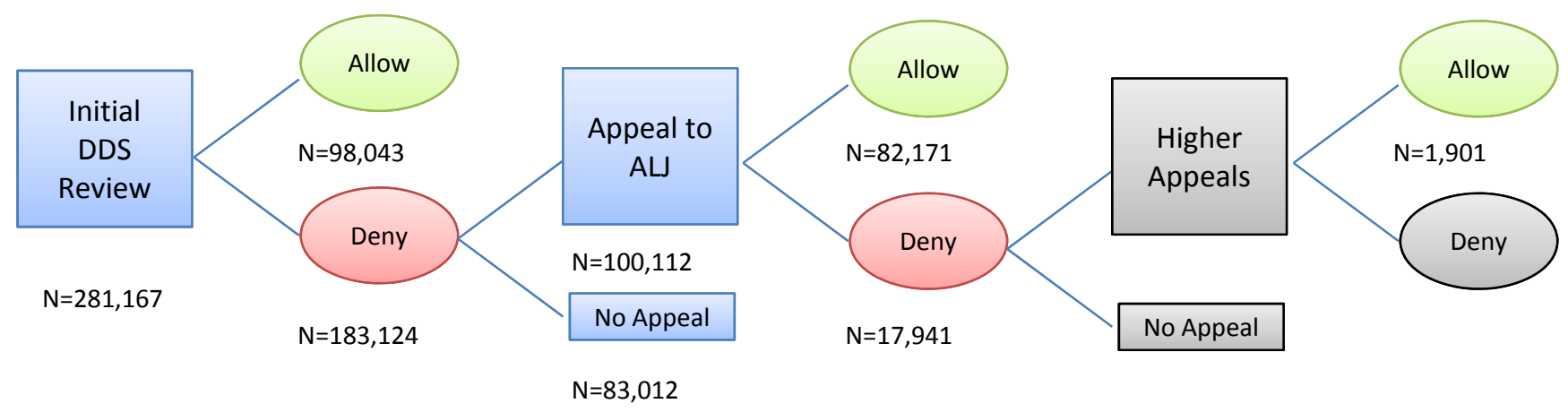


Figure 3. Model of the Effects of SSDI Processing Time and Benefit Receipt on Labor Supply

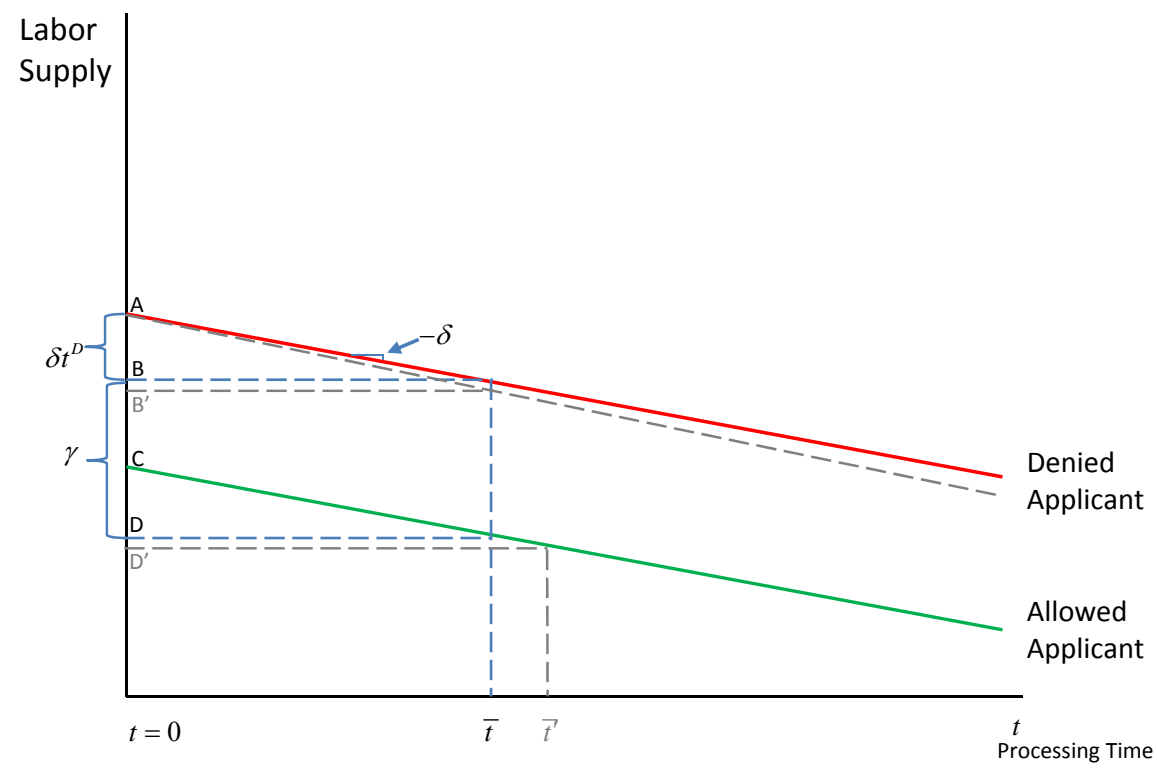




\section{Figure 4}

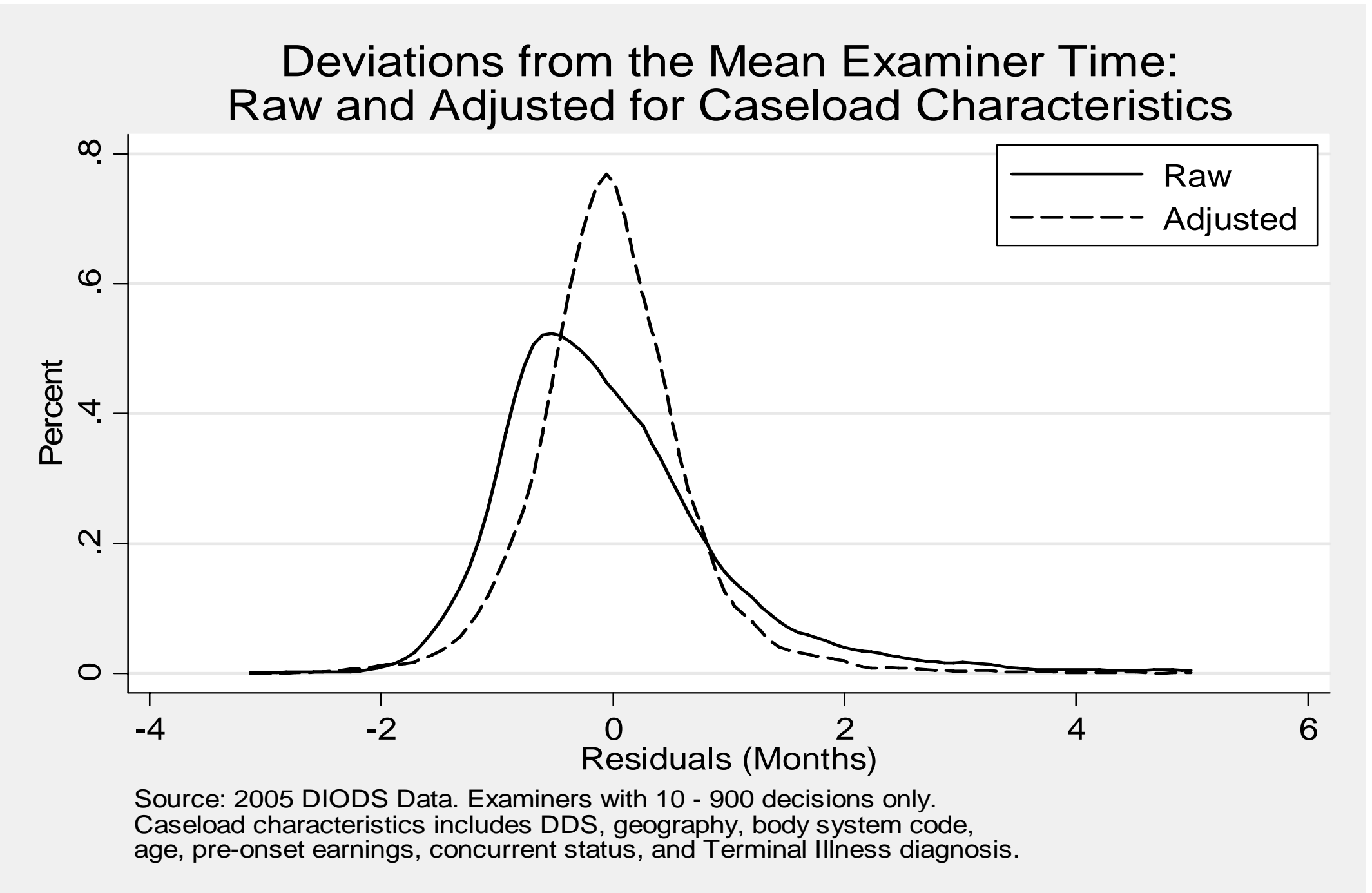

